\title{
3D-mittaukseen perustuva karjan tarkkailu
}

Noora Ruuskanen ${ }^{1)}$, Matti Kurkela ${ }^{2}$, Minna Toivonen ${ }^{3)}$, Mikko Maksimainen²), Juho-Pekka Virtanen²), Hannu Hyyppä2), Eija Latomäki ${ }^{3)}$, Mari Mukka-Koivumäki ${ }^{3)}$, Teija Rönkä ${ }^{1)}$, Marika Ahlavuo²), JussiMatti Kallio ${ }^{1)}$

1) Seinäjoen Ammattikorkeakoulu, Ruokayksikkö, Ilmajoentie 52560800 Ilmajoki etunimi.sukunimi@seamk.fi

${ }^{2)}$ Aalto-yliopisto, Insinööritieteiden korkeakoulu, PL 14100,00076 AALTO etunimi.sukunimi@aalto.fi

${ }^{3)}$ Faba osk, PL 40, 01301 Vantaa etunimi.sukunimi@faba.fi

Maatiloille on jo tarjolla digitaalisia ratkaisuja, mutta uusia digitalisaatiota ja älyteknologiaa hyödyntäviä innovaatioita tarvitaan lisää. Peltojen täsmäviljelyn lisäksi yksi selkeä kokonaisuus uuden teknologian hyödyntämisessä on tuotantoeläinten seuranta maatiloilla. "3D-mittaukseen perustuva karjantarkkailu" on esiselvityshanke, jonka tavoitteena on tutkia fotogrammetrian eli kuvilta mittaamisen soveltuvuutta naudan rakenteen mittaamiseen.

Eläinten 3D-mittaukseen liittyy huomioon otettavia erityispiirteitä: 1) Miten määritellään mitattavan eläimen mitat, mikäli eläimellä on niin paksu turkki, että oikeiden mittojen havainnointi koskettamatta on vaikeaa. 2) Mittaus on toteutettava useilla eri mittalaitteilla samanaikaisesti, jotta mallista saadaan lyhyessä ajassa kattava. 3) Mittauksen keston on oltava erittäin lyhyt, koska kohde ei tietoisesti osaa pysytellä liikkumattomana. 4) Eläinten hyvinvointi mittaamisen aikana ei vaarannu. Navettaympäristön haasteita ovat mm. kameran sijoittaminen, mittauksen esteenä olevat rakenteet, eläinten liikkuminen ryhmissä ja valaistus.

Esiselvityshankkeessa tutkitaan niitä toimintatapoja, joita tarvitaan eläimen rakenteen mittaukseen maatilalla. Hankkeessa selvitetään tietojen tallentamista sähköisesti järjestelmään, josta tieto olisi luettavissa paikasta ja ajasta riippumatta. 3D-mittausteknologian avulla pyritään saamaan objektiivinen näkemys naudan rakenteesta. Eläimestä eri ajanjaksoina otettuja kuvia vertaamalla voidaan seurata sen kuntoluokan ja kasvun kehitystä. Kuvasarjoista voidaan myös havaita poikkeamia eläimen normaalista kunnosta ja tietoa voidaan hyödyntää sairauksien ehkäisemisessä.

Erilaisia fotogrammetriaan perustuvia mittaustekniikoita kokeillaan Seinäjoen Ammattikorkeakoulun Ilmajoen kampuksen tutkimusnavetassa ja eteläpohjalaisilla maitotiloilla. Hankkeeseen osallistuvilta tiloilta voidaan kerätä ainutlaatuista tietoa eläinaineksen ja eläinten hyvinvoinnin kehittämiseen. Samalla selvitetään, soveltuuko valittu teknologia tulevaisuudessa helpottamaan jalostusasiantuntijoiden ja eläinlääkäreiden työtä sekä hyödyttämään maatilayrittäjiä.

Asiasanat: 3D-skannaus, lehmän rakenne, digitalisaatio 


\section{Johdanto}

Lypsylehmien rakenne on yksi keskeisistä jalostusvalintaa varten kerättävistä tiedoista. Rakenneominaisuuksilla on yhteyttä mm. lehmien kestävyyteen ja utareterveyteen (Fogh ym. 2013). Rakennearvostelussa arvioidaan lehmän utaretta, jalkoja ja runkoa; yhteensä yli 20 eri ominaisuutta (engl. Conformation recording of dairy cattle). Ominaisuuksien arviointiasteikko perustuu osin tarkasti määriteltyihin senttimetrimittoihin, osin silmämääräiseen arviointiin. Kuntoluokitus on ensisijaisesti ruokinnan seurantakeino, ja siinä arvioidaan rasvan kertymistä mm. selkärangan, lantion ja hännänjuuren tyven alueelle. Kuntoluokan vaihtelut ovat yhteydessä mm. aineenvaihdunnallisiin sairauksiin, hedelmällisyyteen ja tuotokseen (Roche ym. 2009). Nykyisin kuntoluokitus tehdään silmämääräisesti ja mahdollisesti sen lisäksi eläintä tunnustellen. Markkinoilla on myös 3D-kuvaan perustuva kuntoluokkakamera (DeLaval kuntoluokkakamera BCS).

Käyttäen useaa eri suunnista otettua kuvaa, voidaan kohteesta rekonstruoida 3D-malli (Siebert ja Marshall 2000). Fotogrammetrisillä menetelmillä voidaan toteuttaa esimerkiksi kolmiulotteinen konenäkeminen ja mittaus teollisuuden laaduntarkkailussa (Sansoni ym. 2009). Kuvapohjaisen mittauksen (fotogrammetria) lisäksi kolmiulotteista mittausta voidaan suorittaa joukolla eri teknologioita, joita yleensä kutsutaan 3D-skannaukseksi.

Tämän esiselvityshankkeen tavoite on tutkia, voiko 3D-skannauksella ja fotogrammetrialla mitata navettaolosuhteissa esimerkiksi jalostusasiantuntijoiden ja eläinlääkäreiden tarvitsemaa tietoa. Tuotetun mittaustiedon tulisi olla sovellettavissa kuntoluokan ja hyvinvoinnin selvittämiseen.

\section{Materiaalit ja menetelmät}

\section{Mittalaitteet}

3D-mittaamiseen käytettiin kolmea eri laitetta: 1) kahdeksan kameran monikamerajärjestelmää, joka toteutettiin käyttäen Raspberry Pi 2.0 -kameroita. 2) Occipital Structure Sensor 3D-skanneria ja 3) Lenovo Phab 2 Pro -puhelinta, jossa on syvyyskuvia ottava Google Tango -sensori. 3D-mittauksiin yhdistettyyn lämpökamerakuvaamiseen käytettiin TROTEC IC080L lämpökameraa ja FLIR Lepton 3 pienoislämpökameraa.

\section{Tutkimusnavetta}

Seinäjoen AMK:n Ilmajoen kampuksella sijaitsevan opetusmaatilan navettaa hyödynnettiin kuvapohjaisen mittauslaitteiston kehitystyössä. Tilalla on paikat noin 40 lypsylehmälle ja nuorkarjalle, sekä lypsyrobotti ja lypsyasema. Pihatossa on käytössä kaksi ruokintakioskia, joita hyödynnettiin mittauksissa, koska syödessään eläimet luonnostaan pysyivät melko hyvin paikoillaan. Lehmää kuvattiin takaapäin, jolloin kamerat oli sijoitettu ruokintapöydälle, ruokintakioskin edustalle.

\section{Maitotilat}

Mittauslaitteistoa testattiin viidellä eri maitotilalla Etelä-Pohjanmaan Ilmajoella ja Jalasjärvellä. Jokaisella tilalla oli pihattonavetta. Kahdessa navetassa oli käytössä lypsyasema, ja kolmella lypsy hoidettiin roboteilla. Tilat olivat eri kokoisia, lypsylehmämäärän ollessa 40-160 eläimen väliltä. Jokaiselle navetalle tehtiin alkukartoitus, jossa selvitettiin navetan rakenteet, valaistusolosuhteet, eläinliikenne ja ruokintalaitteistot. Pohjaratkaisut ja valaistusolosuhteet olivat erilasia. Tietojen perusteella voitiin arvioida etukäteen kameroiden sijoittelua. Jos navetassa oli käytössä rehukioski, kamerat sijoitettiin kioskia vastapäätä, jolloin eläintä kuvattiin takaapäin. Muissa tapauksissa eläimiä kuvattiin muun muassa kokoomatilassa lypsyvuoroa odottaessa, poistuessa lypsyltä tai lypsyn aikana lypsyrobotissa. Kamerat sijoiteltiin eläinten ulottumattomiin, esimerkiksi parsirakenteisiin tai tarkkailukäytävälle. Ruokintapöydältä kuvattaessa kameroita kiinnitettiin rakennustelineisiin. Kuvaustilanteesta ja mittauslaitteiston sijainnista pyrittiin saamaan eläimille mahdollisimman häiriötön. 


\section{Tulokset}

Monikamerajärjestelmällä tallennettiin kahdeksan kuvan kuvajoukkoja. Kuvajoukoille tehtiin fotogrammetrinen vastinpistetunnistaminen ja kameroiden tarkka orientointi. Pistepilvelle määriteltiin akselien asemointi, poistettiin lehmään kuulumattomat pisteet sekä tehtiin kohinasuodatus. Rekonstruoidulle kolmiulotteiselle pistepilvelle suoritettiin piirteiden tunnistus. Suodatettu pistepilvi kolmioitiin kolmioverkkopinnaksi (Kuva 1).

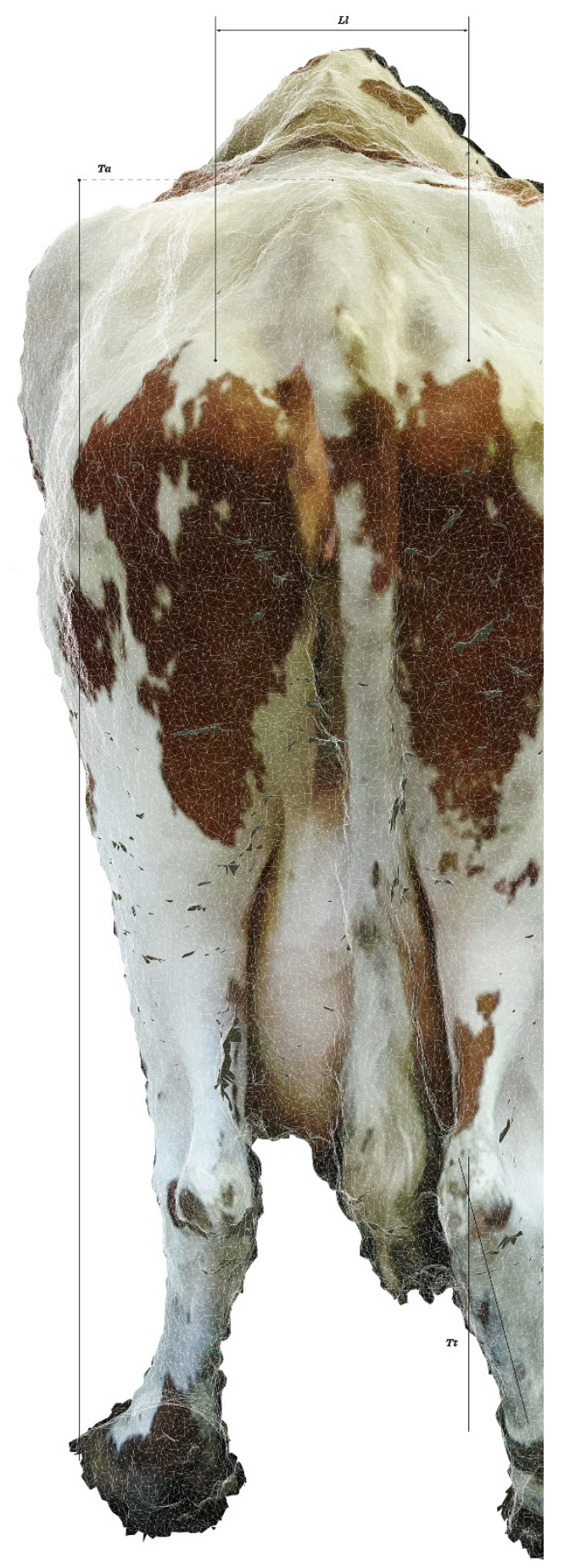

Kuva 1. Monikamerajärjestelmällä mitattu teksturoitu 3D-malli lehmästä. Mallista voidaan laskea mittoja, kuten takakorkeus $\left(\mathrm{T}_{\mathrm{a}}\right)$ lonkkakyhmyjen kohdalta, lantion leveys $\left(\mathrm{L}_{l}\right)$ tai takajalkojen asento takaa $\left(\mathrm{T}_{\mathrm{t}}\right)$. 


\section{Tulosten tarkastelu}

Lehmää ei saatu mallinnettua kokonaisuudessaan täydellisesti. Testimittauksista saaduista 3D-malleista, joita saatiin lehmän takaosasta tai sivuprofiilista, pystyy hahmottelemaan eläimen mittasuhteita, jalkaasentoja ja kuntoluokkaa

Opetusnavetassa ja tutkimukseen osallistuneilla tiloilla havaittiin, että kameroiden sijoittelu on suunniteltava huolellisesti. Kameroilla saavutettu näkymä määrittelee myös syntyvän 3D mittaaineiston kattavuuden. Kamerat ja niiden kiinnitysmekanismit herättivät lehmien huomion. Täten kamerat oli saatava eläinten ulottumattomiin, jotta laitteet eivät rikkoudu ja eläin ei esimerkiksi vahingossa niele vierasesineitä. Myös valaistus oli tärkeä tekijä mittausten onnistumisen kannalta. Navetassa pitää olla riittävästi luonnonvaloa tai keinovaloa, jotta mittaus onnistuu. Tumma, lähes yksivärinen eläin on vaikea kuvattava hämärässä navetassa. Toisaalta navetassa mittausten eduksi ovat erilaiset pinnan tekstuurit kuvapohjaisessa mittaamisessa. Sen sijaan rakenteet, esimerkiksi parret ja pylväät, aiheuttivat katveita mittausdataan. Tutkimuksessa arvioidut pihattonavetat olivat valoisia ja avaria. Valon määrä helpotti mittaamista, mutta kameroille saattoi olla vaikea löytää pihatosta sopivaa sijaintia. Lypsyrobotti tai -asema oli usein kätevin paikka, sillä lehmä keskittyi lypsyyn eikä itse mittaustilanteeseen. Ruuhkaisissa paikoissa yksittäisen lehmän mittaus oli hankalaa.

Eläinten 3D-mallintaminen on yksi menetelmä eläinten seurantaan täsmäkotieläintuotannossa. Varsinkin isoilla karjatiloilla menetelmä voi olla hyödyllinen osa karjan hyvinvoinnin seurantaa ja jalostussuunnittelua. Teknologian kehittyessä 3D-mittaaminen muuttuu yhä helpommaksi, mutta malleista saatavan tiedon käyttäminen tuotannon hyväksi on tärkeässä roolissa. 3D-malleista saatava tieto on maitoyrittäjän apuna ruokinnan ja jalostuksen suunnittelussa, sekä sairauksien ennaltaehkäisyssä. Tiedon jakaminen eläinlääkärin ja jalostusasiantuntijan kanssa voi lisätä 3Dmalleista saatavaa hyötyä. Lopulliset tulokset saadaan projektin päätyttyä keväällä 2018.

\section{Johtopäätökset}

Tässä tutkimuksessa selvisi, että naudan osittainen 3D-mittaaminen ja mallintaminen oli mahdollista käyttäen monikamerakuvausta tai 3D-skanneria. Useimmiten mitattavan eläimen liikkumattomuus oli varminta joko väkirehukioskin luona, eläimen jonottaessa lypsyrobottiin pääsyä tai poistuessa lypsyrobotista. Kaikkein mielekkäintä olisi kuitenkin, että mittalaite olisi integroitu osa lypsyrobottia. Jos tilalla on esimerkiksi asemalypsy, eikä käytössä rehukioskeja, mittalaitteen sijoittelu voi olla haastavaa. Eläimen täytyisi pysyä mittauskohdassa liikkumatta ja kameran pitäisi olla sijoitettuna optimaalisesti kattavan mittaustuloksen saamiseksi. Asemalypsyssä mahdollisia sijoituspaikkoja voisivat olla esimerkiksi kokoomatilassa tai naudan poistuessa asemalta. Pienillä karjamäärillä, parsinavetassa tai naudanlihantuotannossa vuokrattava ja helposti liikuteltava tai käsivaralla kuvaava mittalaite lienee käytännöllisin ratkaisu.

3D-mallin avulla pystyy seuraamaan eläimen kuntoluokan kehitystä. Sopivan kuntoluokan avulla voidaan ehkäistä naudan mahdollisia ongelmia eri tuotoskauden vaiheissa. Lehmän rakennetta arvostellessa rakennearvostelija arvioi silmämääräisesti eläimen sen hetkisessä kunnossaan. 3D-mallien avulla voitaisiin saada objektiivista pitkän aikavälin dataa, jolla lisättäisiin arvosteluvarmuutta. Mallista saisi myös laskettua tarkasti eläimen mittasuhteita. Eläinlääkäri voi havainnoida malleista eläinten hyvinvointia ja jalkaterveyttä, kuten onko eläimissä esimerkiksi ruhjeita tai seisooko se normaalisti. Liikkeen mallintaminen toisi mahdollisuuden ontumien ja muiden jalkasairauksien varhaiseen havaitsemiseen.

Maitotilayrittäjän näkökulmasta 3D-malleista olisi eniten hyötyä, mikäli mallit olisivat helposti hyödynnettävissä ja ne voitaisiin yhdistää tuotosseurannan tai tuotannonohjausjärjestelmistä saatavan tiedon kanssa. Jatkokehityksessä tulisi ottaa huomioon datan järkevä käsittely. Mittaustilanteessa laitteen tulee tunnistaa eläin, ja 3D-mallin pitäisi olla lähes heti tarkasteltavissa helppokäyttöisessä ohjelmassa. Parhaimmassa tapauksessa rakennearvostelussa käytettävät mitat tulkittaisiin 3D-malleista 
automaattisesti. Maitotilayrittäjä voisi itse päättää, jakaako hän mallin katseluoikeuden muille käyttäjille, kuten eläinlääkärille tai jalostusasiantuntijalle.

\section{Kiitokset}

Esiselvityshanke on rahoitettu Manner-Suomen maaseudun kehittämisohjelmasta Leader-ryhmä Liiverin kautta. Muita rahoittajia ovat Faba osk ja hankkeeseen osallistuvat maatilat. Haluamme kiittää rahoittajia, mittauslaitteiden testaukseen osallistuneita maatiloja ja hankkeen ohjausryhmää hankkeen toteuttamisen mahdollistamisesta.

\section{Kirjallisuus}

Conformation recording of dairy cattle. International committee of animal recording. http://www.nordicebv.info/wp-content/uploads/2015/05/Conformation_recording_pictures.pdf DeLaval kuntoluokkakamera BCS. http://www.delaval.fi///Tuotteet/Management/Systems/1/ Fogh, A., Paakala, E. \& Carlen, E. 2013. Mitkä rakenneominaisuudet vaikuttavat utareterveyteen ja kestävyyteen? http://www.nordicebv.info/wp-content/uploads/2015/04/What-conformation-traits-are-importantfor-the-healthy-and-long_final_FIN.pdf

Roche, J. R., Friggens, N.C, Kay, J.K., Fisher, M.V., Stafford, K.J. \& Berry, D.P. 2009. Invited review: Body condition score and its association with dairy cow productivity, health, and welfare. Journal of Dairy Science 92: 5769-5801.

Sansoni, G., Marco Trebeschi, M. \& Docchio, F. 2009. State-of-The-Art and Applications of 3D Imaging Sensors in Industry, Cultural Heritage, Medicine, and Criminal Investigation. Sensors 9: 568-601. https://doi.org/10.3390/s90100568

Siebert, J.P. \& Marshall, S.J. 2000. Human body 3D imaging by speckle texture projection photogrammetry. Sensor Review 20: 218-226. https://doi.org/10.1108/02602280010372368 